\title{
Documenting the Adverse Impact of Resume Screening: Degree of Ethnic Identification Matters
}

\author{
Eva Derous \\ Ghent University, Belgium \\ Ann Marie Ryan \\ Michigan State University, U.S.
}

\section{Reference:}

Derous, E., \& Ryan, A. M. (2012). Documenting the adverse impact of resume screening:

Degree of ethnic identification matters. International Journal of Selection and Assessment. 


\begin{abstract}
We investigated adverse impact of resume screening taking into account the intersectionality of minority characteristics. A correspondence audit test showed hiring discrimination depended on the strength of applicants' ethnic identification. The odds for rejection were 4-6 times higher for resumes with ethnic minority identifiers (Arab names; Arab affiliations) when compared to ethnic majority identifiers (Dutch names; Dutch affiliations). Sex moderated the ethnicity effect but the particular effect (ethnic prominence; double jeopardy against females or males) depended on the type and degree of ethnic identification, lending support for a within-category approach to study ethnic prejudice. The four-fifths rule resulted in similar findings. Theoretical implications regarding the intersectional effects of minority characteristics and practical implications regarding ways to avert adverse impact during resume-screening are discussed.
\end{abstract}




\section{Documenting the Adverse Impact of Resume Screening: Degree of Ethnic Identification Matters}

Resumes are one of the most important sources of information when recruiters initially screen applicants for jobs (Piotrowski \& Armstrong, 2006). Recruiters can easily infer undisclosed personal characteristics such as ethnicity from resume characteristics such as name (Bennington \& Wein, 2002) and social group affiliations (Dovidio \& Gaertner, 2000). Models of impression formation (Brewer, \& Harasty Feinstein, 1999; Fiske, Lin, \& Neuberg, 1999) further suggest category-based information processing will be particularly strong when limited individualized information is available. Because individuating information on paper resumes is rather limited, applicants may be perceived in category-based, stereotypic ways which can lead to biased decisions, particularly so for ethnic minority applicants.

The present study contributes to research on discriminatory resume-screening in several ways. Previous studies typically focused on the statistical significance of group differences in ratings (i.e., ethnic minorities receiving lower job suitability ratings than ethnic majorities). However, real-world applied contexts also focus on practical rules for determining the existence of ethnic discrimination, such as the four-fifths rule (Bobko \& Roth, 2010). In this study, we also consider practical indicators of discrimination. Second, it is unclear whether all ethnic minority applicants are equally subject to hiring discrimination (Derous, Nguyen, \& Ryan, 2009; Derous, Ryan, \& Nguyen, 2012); we investigated whether rejection rates of ethnic minority applicants depend on the degree to which one is seen as very connected to one's ethnic group, via not just an ethnic name but also activities that suggest a strong identification with one's ethnicity. In addition, we explored whether ethnic identifiers on resumes lead to more discriminatory effects in either an additive or multiplicative way. Third, much experimental research has examined 
dimensions of diversity independent from each other, irrespective of personal and contextual factors as potential moderators (Riordan, Schaffer, \& Stewart, 2005). We therefore studied the intersectional effects of applicant sex and ethnicity. Browne and Misra (2003) further noted that there is a need to specify the conditions under which minority characteristics might become more salient. We also investigated whether intersectional effects of sex with ethnicity were contingent upon degree of ethnic identification. Finally, since the September $11^{\text {th }}$ attack in 2001 , individuals of Arab descent have increasingly reported experiencing social prejudice and labor discrimination in Western nations. Yet, few studies have investigated actual hiring decisions/discrimination towards Arab applicants during the resume-screening phase; we do so in this study. Furthermore, because many studies on resume screening are conducted among students (e.g., Derous et al., 2009) we examined real recruiters using a correspondence audit test in order to enhance the ecological validity of study findings.

\section{Ethnic Identification}

According to the ethnic prominence model (Levin, Sinclair, Veniegas, \& Taylor, 2002), ethnicity is a more influential factor in decision-making than other social category information. . Ethnic minorities' identification with their group might trigger actual discrimination because of the actual or symbolical threat as perceived by the ethnic majority and the more threatening nature of ethnicity compared to other minority characteristics. For instance, ethnic majority group members (e.g., Dutch) may perceive those of lower status groups who strongly identify with their own ethnic minority groups and strive for their minority group interests as an attack to the legitimacy of the status quo. Any perceived attack to the status quo might be restored by discriminatory actions from the part of the majority member (Derous et al., 2009). Furthermore, the degree to which ethnic minorities visibly identify with their ingroup may influence category- 
based processing and hence the strength of discriminatory decision-making (Kaiser \& PrattHyatt, 2009). For instance, recruiters tend to react more negatively towards ethnic minority applicants with a dark skin tone than a fair skin tone (everything else held consistent) (e.g., Maddox, 2004).

In resume-screening, the saliency level of applicants' ethnic group identity may be conveyed to prospective employers via ethnic-sounding names and ethnic group affiliations as appearing on job resumes. Names are a substantial part of one's social identity (Erwin, 1999) and have been related to expectations of intelligence, popularity, and job success (Bruning, Polinko, Zerbst, \& Buckingham, 2000) but are also evidenced as a source of employment discrimination. For instance, correspondence studies in Germany (Kaas \& Manger, 2011) revealed fewer callbacks for applicants with a Turkish name than a German name all other characteristics being equal. A Swedish correspondence study (Carlsson \& Rooth, 2008) showed that applicants' names (native vs. foreign-sounding) explained approximately 77 per cent of the differences in the probability of being invited to an interview between native and immigrant applicants. Similar findings have been reported in the United States for Black and Hispanic names vis-à-vis traditionally Anglo names (Bertrand \& Mullainathan, 2004).

Another indicator of ethnic identity found on resumes is applicants' affiliation with sociocultural groups (Dovidio \& Gaertner, 2000). While names can convey one's ethnic origin, they do not convey how much one identifies with an ethnic group. Affiliation, on the other hand, indicates the loyalty to a group's shared history and common cultural inheritance and applicants' religious, political, and ethnic affiliations may affect recruiters' decision-making. Applicants with certain religious and political affiliations, for example, experienced more hiring 
discrimination in the Turkish police (Caglar, 2004). Similar findings have been reported for applicants’ ethnic group affiliations (Horverak, Bye, Sandal, \& Ståle Pallesen, 2011).

Recently, scholars have argued for consideration of dimensions of variability within minority categories for a better understanding of discrimination and prejudice perceptions (i.e., within-category approach; see Kaiser \& Pratt-Hyatt, 2009). In line with these suggestions, we expected recruiters to reject ethnic minority applicants in proportion to their outgroupness (i.e., the ethnic identification hypothesis) Specifically, we expected hiring discrimination to be contingent upon the strength of ethnic identifiers on resumes (i.e., ethnic-sounding names and affiliations) in such a way that:

Hypothesis 1. Resumes of applicants with higher levels of ethnic minority identifiers (i.e., Arab name and affiliations) will receive more rejections than those of equally qualified applicants with mixed ethnic minority-majority identifiers (e.g.., Arab name and Dutch affiliations), and those with ethnic majority identifiers (i.e., Dutch name and affiliations).

Strong ethnic identification may lead to strong discriminatory effects. However, what is less clear is how ethnic identifiers affect discriminatory outcomes. Berdahl and Moore (2006) suggested minority characteristics to affect discriminatory decision-making in either additive or multiplicative ways. An additive model would suggest that applicants with both Arab-sounding names and Arab affiliations would experience discriminatory effects equivalent to the sum of the amounts experienced by those with only one ethnic minority identifier (i.e., either an Arab name or Arab affiliations). The multiplicative model, on the other hand, states that the disadvantages of ethnic identifiers multiply each other, making the discriminatory effect of applicants with both an ethnic minority name and group affiliations greater than the additive hypothesis would suggest. 
As we are not aware of previous studies that have examined this issue, we formulated the following research question:

Research Question. Will ethnic identification effects be either additive or multiplicative in nature?

\section{Double Jeopardy}

According to the ethnic identification hypothesis, the strength of identification with an ethnic group should be an influential factor in judging applicants. However, applicants likely have multiple social identities as they belong to multiple groups (Ashkanasy, Härtel, \& Daus, 2002). The multiple minority status model (also referred to as double or multiple jeopardy) suggests that other characteristics, such as sex, may have additive or moderating effects on ethnic discrimination (Nelson \& Probst, 2004). Two competing hypotheses have been set forward regarding the intersection of ethnicity and sex and evidence for both hypotheses has been reported (Derous et al., 2012).

First, the double jeopardy hypothesis (Browne \& Misra, 2003) focus specifically on the intersection of ethnicity and sex, suggesting that ethnic minority females experience the most discrimination due to their 'double' outgroup status. For instance, minority women may experience more workplace harassment (Berdahl \& Moore, 2006) and appear to earn less and to have less authority in the workplace when compared to majority women and minority/majority men (Browne, Hewitt, Tigges, \& Green, 2001). Alternatively, the subordinate male target hypothesis (Sidanius \& Pratto, 1999) suggests that ethnic minority men suffer the most discrimination compared to ethnic women and majorities, particularly in male-dominated domains (such as employment) because threat and conflict are predominantly associated with intergroup competition among men. For instance, Bendick, Jackson, Reinoso, and Hodges (1991) 
showed that Latino male applicants were less likely to be invited for a job than Latino female applicants and Anglo applicants, all qualifications being equal.

Given that support for both the double jeopardy and the subordinate male target hypotheses exists, it is important to consider how context influences how the intersection of ethnicity and sex might be viewed by recruiters. In the Netherlands, Arab men may be perceived as most threatening since they regularly compete with host nationals for jobs in a narrow concentration of low skill jobs (OECD, 2008). Dutch employers also have more negative stereotypes of Arab men than Arab women: Arab women are considered as less dominant, less aggressive, more trustful and more conscientious than Arab men. Also, Arab males are more frequently associated with criminal offences than Arab females and Dutch males/females (Blom, Oudhof, Bijl, \& Bakker, 2005). We therefore expected higher rejection rates and more adverse impact (see further) for the Arab male profiles in resume screening for low skill jobs. That is, we posit that the subordinate male target hypothesis will receive support and the double jeopardy hypothesis will not in this particular context.

Hypothesis 2. Ethnicity effects will be moderated by applicants' sex such that resumes of ethnic minority male applicants (i.e., Arabs) will receive more rejections than those of their female counterparts and those of ethnic majority applicants (i.e., Dutch).

\section{Indicators of Discrimination}

Somewhat different perspectives and approaches to examining discrimination have been reported in the literature. In a more general sense, adverse impact reflects the possibility of unfairness in employment-related decision making against any subgroup (e.g., ethnic minorities, the elderly, etc.) (Higuera, 2001). However, in its original sense, adverse impact is a legal term that refers to a 'substantially different rate of selection for one group relative to another (Tippins, 
2010 , p. 201) and which is - aside from tests of statistical significance - often calculated using the four-fifth (or $80 \%$ ) rule. Specifically, a selection rate for any race, ethnic or sexual group that is less than four-fifth of the group with the highest rate is generally regarded as evidence of adverse impact (Zedeck, 2010). A similar standpoint regarding adverse impact is taken by the European Economic Council (EC Employment Framework Directive; European Communities, 2000). Adverse impact does not by itself establish discrimination but only a presumption of discrimination unless the employer can prove a business necessity for using a test with adverse impact or can demonstrate job relatedness, i.e., a clear relationship between the test and job criteria. Overall, there is substantial overlap in the definition of adverse impact and the evidence needed to specify adverse impact between the United States and Europe. However, contrary to the United States, Europe has not yet promoted any specific rule for assessing adverse impact and there is much flexibility in how hiring discrimination can be demonstrated (e.g., through situation testing or statistical evidence; Hanges \& Feinberg, 2010).

Typically, the four-fifth rule has been applied to tools for personnel selection, such as personality tests (e.g., Ones \& Anderson, 2002), cognitive ability tests (e.g., Pulakos \& Schmitt, 1996), work sample tests (e.g., Bobko, Roth, \& Buster, 2005), SJTs (e.g., Chan \& Schmitt, 1997), assessment centers (e.g., Dean, Roth, \& Bobko, 2008), interviews (e.g., Moscoso, 2000), physical ability tests (e.g., Lonsway, 2003), and any combination of two or more of these tests (e.g., Ryan, Ployhart, \& Friedel, 1998; Potosky, Bobko, \& Roth, 2005). However, to our knowledge, the four-fifth rule has not been examined in the research literature in relation to resume screening. In this paper, we examine the adverse impact of resume screening in terms of statistically significant differences in group rejection rates but also in terms of practical indicators, such as the four-fifth rule as defined by the UGESP. 


\section{Method}

We used a situation test, namely the correspondence audit test, to measure rejection rates and adverse impact against Arab-identified applicants during the resume screening phase. The correspondence audit technique allows comparing labor market outcomes of applicants who are equally qualified for a job and identical in all productive characteristics but only differ in demographic variables (e.g., ethnicity, sex, affiliations), as presented on their application letters or resumes. By sending out the matched applications to the same job opening and by counting the callback (rejections or invitations), differential treatment by recruiters can be attributed to hiring discrimination (see Derous et al., 2012, for a similar approach).

\section{Design}

The correspondence audit test consisted of a 2 (Name) by 2 (Affiliation) by 2 (Sex) mixed-factor design. Name and Affiliation were within-subjects factors: Each resume was assigned either a Dutch or Arab first/last name (e.g., Janneke Janssen vs. Semra Shadid) and Dutch or Arab affiliations (e.g., active member of the Dutch Youth Association vs. Arab Youth Association). As such, four applicant profiles were created: a highly Dutch-identified profile (Dutch name and affiliation), a mixed Dutch-Arab profile (Dutch name and Arab affiliation), a mixed Arab-Dutch profile (Arab name and Dutch affiliation), and a highly Arab-identified profile (Arab name and affiliation). Applicant sex was measured between-subjects and was indicated on the resume (male vs. female). Job type was kept constant (jobs in the service sector like desk clerk; medium vocational-level; gender-neutral).

\section{Procedure}

In total we sent 600 resumes or applications to 150 advertisements (i.e., 4 resumes per advertisement) and counted the responses (i.e., no response, rejection, invitation). Because 
employers can contact applicants either by email, postal mail or phone, we used eight different mailing addresses, email accounts, and phone numbers. Specifically, eight contact persons, who were blind for the experimental goal, provided their mailing addresses, checked letters, and forwarded letters weekly to the experimenter. Eight phone cards with different cell phone numbers (one per applicant) were purchased for the study. There was a standard voice mail for each phone number with a standard outgoing message ("This is the voicemail of 06-11223344. Please leave your message after the beep"). When an applicant got rejected, no further interaction occurred with the employer. When an applicant got invited, the offer was renounced (i.e., by mentioning that one was not available anymore).

\section{Materials and pilot testing}

In a series of pilot studies preceding this study we developed and tested the experimental materials. A similar approach was followed as in Derous et al. (2012). First, we selected a pool of job advertisements covering jobs at a semi-skilled level that were posted on electronic job search databases within a metropolitan area. Advertisements were selected where applicants were asked to email their resume; we eliminated any advertisement where applicants were asked to call or to appear in person. Two independent raters evaluated the advertised jobs on sector (service), gender neutrality (equally accessible for men and women) and educational requirements (middle-level vocational training). In a second phase, we developed the resume templates. We took resumes of actual job seekers that were posted on a job search website in the area of interest (the person's name and contact information was deleted) as a basis for creating resume templates. The templates included information on (a) applicants' age (23-25) and sex (male-female), educational level (middle-level vocational training) and (c) kind or work experiences for service jobs (e.g., customer services, restaurant business). In a third phase, the 
resume templates were evaluated on equivalence in a paired-wise order by 48 participants. The following characteristics were evaluated: socio-economic status, applicant age, educational level/type, work experience, overall resume quality and overall equivalence. Finally, participants evaluated names, affiliations, and sex of the fictitious applicants as appearing on the resumes. Both names and affiliations were collected from previous studies (see for pilot testing: Derous et al., 2009) in order to integrate on the resumes. Based on the pilot test results, aspects were integrated together to formulate eight full resume templates; work experiences/educational requirements were tailored to the specific job vacancies/requirements. (Detailed results of the pilot tests can be obtained from the author).

\section{Results}

\section{Preliminary analyses}

We removed 10 vacancies because the company website was unavailable or the vacancy was removed while we applied, which resulted in a sample of 140 vacancies. Furthermore, we excluded all vacancies $(n=40)$ with missing cases (i.e., when less than 4 resumes received a response) since a non-response might reflect factors unrelated to discrimination, such as lost letters, etc. (Riach \& Rich, 2002). This resulted into a final sample of 100 vacancies (i.e., 400 resumes with a complete response) reflecting a response rate of $66 \%$. Because some researchers suggest that a non-response might reflect a rejection instead of factors unrelated to hiring decisions (e.g., de Beijl, 2000), we additionally conducted chi-square analyses on missing cases. Specifically, some form of differential treatment and/or subtle discrimination might be assumed if the non-response to some resumes (e.g., those of minorities) is higher than that of others (e.g., those of majorities). Missing data analyses, however, showed no differential treatment of the applicant profiles, $\chi^{2}(6)=5.07, p=.53$, suggesting that applicant profiles were equally 
vulnerable to non-response/response. In order not to confound outcomes with factors unrelated to hiring discrimination and in line with previous studies (Derous et al., 2012) we proceeded testing our hypotheses on vacancies for which we received a complete response (either rejection or invitation).

\section{Hypothesis Testing}

Hypothesis 1 was tested using logistic regression and chi-square analyses. A test of the full model with all three predictors and their interactions against a constant-only model was

statistically significant, $\chi^{2}(7)=179.79, p<.001$, indicating that the predictors, as a set, reliably affected the response to the resume. The model accounted for between $39 \%$ and $52 \%$ of the variance in the response. According to the Wald criterion, applicants' Sex did not predict whether there was a callback; all other main effects and several interactions were significant (Table 1). Rejection of resumes was significantly enhanced for applications with an Arab name compared to applicants with a Dutch name, with the odds for rejection being 4.86 times higher for resumes with an Arab name. A main effect of Affiliation also occurred: The odds for rejection was 6.74 higher for resumes with an Arab affiliation than for resumes with a Dutch affiliation. The two-way interaction between Name and Affiliation supported Hypothesis 1 (Figure 1; Table 1) (This is qualified by the three-way interaction of Sex with Name and Affiliation discussed below; Figure 2). Specifically, a series of chi-square analyses with Bonferroni correction showed that applicants with Arab identifiers (i.e., name; affiliation) were rejected more often than those without any Arab identifier (comparisons 1.1 till 1.3 in Table 2). In support of the ethnic identification hypothesis (Hypothesis 1), highly identified profiles were rejected more often than those with only an Arab affiliation (comparison 1.5 in Table 2) or ethnic name (comparison 1.6 in Table 2). We also explored whether the Name by Affiliation 
interaction was either additive or multiplicative in nature (Research Question). The main effects of the ethnic identifiers (Name and Affiliation), as well as their significant interaction effect lend support for the multiplicative model (Figure 1).

The adverse impact of resume screening was further determined by a four-step process (Zedeck, 2010). First, we calculated the selection rate (SR) for each applicant profile (i.e., highly Dutch-identified, mixed Dutch-Arab identified, mixed Arab-Dutch identified, and highly Arabidentified applicant profile). In total, we calculated 12 selection rates (Table 3): Four SRs for the total group ( $N=400$ resumes), four SRs for the female applicants $(N=212$ resumes), and four SRs for the male applicants $(N=188$ resumes). In a second step, we observed which applicant profiles had the highest selection rates. As can be seen from Table 3, the highly Dutch identified applicant profiles (with both a Dutch name and Dutch affiliation) had the highest selection rates , whereas, the lowest selection rates were found for the highly Arab-identified applicant profiles (with both an Arab name and Arab affiliation). In a third step, we calculated the adverse impact ratios (AI-ratios) by dividing the selection rate for the Arab-identified and mixed applicant profiles by the selection rate of the highly Dutch identified applicant profile (being the applicant profile with the highest SR). Finally, we examined whether the selection rate (SR) for any minority profile was substantially less (i.e., less than four-fifth or $80 \%$ ) than the selection rate for the highest applicant profile. As can be seen from Table 3 the SRs of the highly Arab-identified applicant profiles (Profile 4) and the mixed ethnic identified profiles (Profiles 2 and 3) were always substantially lower than those of the Dutch profiles (Profile 1) in the total group, among the female applicants and among the male applicants. Furthermore, the selection rates of the highly Arab-identified applicant profiles (Profile 4) were always substantially lower than those 
of the mixed profiles (Profiles 2 and 3), in the total group, among the female and male applicants (Table 3). This indicates Hypothesis 1 was supported via a practical indicator of adverse impact. Hypothesis 2 proposed resumes of Arab males would receive more rejections than those of Arab females and Dutch applicants. While Figure 2 shows highly Arab-identified females were rejected more often than highly Arab-identified males, this difference was not significant, $\chi^{2}(1)=1.00, p=.32$ (comparison 2.4 in Table 2$)$. The only significant difference between males and females was found for applicants with a mixed Arab-Dutch profile: Male applicants with an Arab name and Dutch affiliation (comparison 2.3) were rejected significantly more than female applicants with the same profile, $\chi^{2}(1)=11.19, p<.01$. There were no significant differences between males and females for the other profiles, namely the highly Dutch-identified applicants, $\chi^{2}(1)=.33, p=.56$ (comparison 2.1) , and the applicants with a mixed Dutch-Arab profile, $\chi^{2}(1)=.19, p=.66$ (comparison 2.2). Therefore, Hypothesis 2 was partially supported.

To further examine whether any sex differences existed in adverse impact, we calculated the most commonly reported statistics to report adverse impact (the z-test, the Pearson Chisquare test, and the Fisher's Exact Probability test; Tippins, 2010). The AI-ratios for the highly Arab-identified females (AI-ratio Profile $4=.12)$ and males (AI-ratio Profile $4=.18)$ did not differ significantly from each other, $z$ Profile $4=-0.84, p=.40$. There were no significant differences in selection rates of males and females either: $\chi^{2}$ Profile $4(1)=.67, p=.40$; Fisher's exact $p$ Profile $4=$ .57 (two-tailed), meaning that the adverse impact for male and female applicants with both an Arab name and Arab affiliations was equal. However, there was a significant difference in AIratios of the mixed Arab-Dutch females (AI-ratio Profile $3=.79$ ) and males (AI-ratio Profile $3=.36$ ), $z$ Profile $3=3.80, p<.01$. The selection rates of female and male applicants differed: $\chi^{2}$ Profile $3(1)$ $=14.22, p<.01 ;$ Fisher's exact $p_{\text {Profile } 3}<.05$ (two-tailed). Specifically, the adverse impact was 
significantly higher when screening resumes of male applicants with an Arab name and Dutch affiliations, lending support for the subordinate male target hypothesis (Table 3). This provides evidence that practical, commonly used indicators also point to some intersectionality effects in resume screening.

\section{Discussion}

Going beyond many previous findings, the present study demonstrates ethnic identification effects among real recruiters in an unobtrusive way (i.e., through correspondence audit testing). Significantly higher rejection rates and more adverse impact (lower selection rates) were found for the mixed ethnic identified applicants when compared to the Dutch identified applicant profiles. Of particular note, significantly higher rejection rates were found for highly Arab-identified applicants than for mixed Arab-Dutch identified applicants and Dutch applicants, suggesting not just ethnic differences in rejection rates but differences according to the level of identification (for a similar result in the context of a job interview: see Horverak et al., 2011). Results further lend support for a multiplicative effect rather than an additive effect of ethnic identifiers, meaning that ethnic-sounding names and affiliations are not independent and additive categories. Rather, any disadvantage compounds each other, making the disadvantage of having both an Arab-sounding name and Arab affiliations (i.e., strong ethnic identity) greater than the additive version would suggest.

A second contribution regards the intersectionality of ethnicity with sex. Interestingly, we found a significant three-way interaction among applicants' ethnic name, ethnic affiliation, and sex. Closer inspection of the data showed evidence for the subordinate male target hypothesis for the mixed Arab-Dutch identified profiles. Specifically, male applicants with an Arabsounding name and Dutch affiliations were rejected significantly more often than female 
applicants with an Arab-sounding name and Dutch affiliations. Similar findings emerged when the adverse impact ratios were calculated. Prejudice might be more directed towards minority men than women because of the status differences in gender. Furthermore, in Dutch society particularly, Arab females are perceived as less threatening than Arab males. Although highly Arab-identified female applicants were rejected more often than highly Arab-identified males, post-hoc tests showed that this difference was not significant. Perhaps being strongly ethnicallyidentified overshadowed any sex differences, providing support for the ethnic prominence hypothesis among the highly ethnically-identified profiles but not so among the less ethnicallyidentified profiles.

Overall, results suggest it is worse to be a highly ethnically identified minority applicant than to just be a minority applicant who does not draw attention to his/her ethnic/cultural heritage. This finding corroborates Kaiser and Pratt-Hyatt's (2009) lab findings on prejudicedistribution effects: Ethnic majorities react less positively towards strongly identified ethnic minorities than to weakly identified ethnic minorities. A closer inspection of the data further showed that evidence for the intersectionality of ethnicity and sex might depend on the particular ethnic characteristics (name vs. affiliation) and intersectionality that is considered. Specifically, the intersectional effects seemed contingent upon the strength of applicants' degree of ethnic identification. Previously mixed and/or puzzling findings regarding the viability of the double jeopardy hypothesis and the subordinate male target hypothesis, may have not taken into consideration contingencies internal to the applicant, such as type and degree of ethnic identification. Furthermore, in line with Kulik, Roberson, and Perry (2007) we propose that one of an individual's multiple categories may become more salient in hiring contexts depending on category salience cues. For instance, Arab females may be discriminated against when they 
appear in person at the interview, especially if wearing religious attire such as headscarves (e.g., Ghumman \& Jackson, 2010) or when job demands are high (e.g., Derous et al., 2012). As shown, double jeopardy against either ethnic minority females or males may also depend on the strength of the applicant's ethnic identification with the ethnic minority group as well as the ethnic marker that one considers upon decision-making. Future research therefore, should consider multiple categorization effects from both a within- and between category perspective.

Despite the ubiquitous use of resume screening as a first screening instrument, there is little discussion in the research literature of adverse impact rates at this stage of the process. One explanation might be in the nature of the study designs and methodology: Hiring position scenarios using Likert-type ratings do not allow testing for the four-fifth rule, whereas audit tests do. Note, however, that our "applicant pool" consisted of the resumes we sent out rather than a set of resumes received by a given organization for a specific job. While our examination is useful because it puts findings in the context of a practical indicator, any given employer might experience different selection rates, and in particular would likely have lower rates of application by minority group members than what was in our artificial resume pool.

Strengths and limitations. Social psychological theories (like ethnic prominence; double jeopardy) have been postulated in the literature as relevant (Goldman, Gutek, Stein, \& Lewis, 2006) but have not been applied extensively to resume screening; we did so. Specifically, we investigated the adverse impact of resume screening against ethnic minority male and female applicants. Moreover, we used a subgroup approach to study ethnic bias in resume-screening, indicating some applicants to be more vulnerable to out-group derogation than others depending on their degree of ethnic in-group identification (ethnic identification hypothesis). Whereas Kaiser and Pratt-Hyatt (2009) investigated Blacks and Latino male targets in lab settings, we 
further showed evidence for within-category prejudice towards Arab male and female applicants in an applied recruitment setting. Arabs are an ethnic minority group that hasn't received as much attention as other minority groups and this is a current topic of great practical relevance in Western society. We investigated hiring discrimination against Arab males and females by means of a correspondence audit study. Correspondence tests are unobtrusive measures and hence powerful methods to register labor market discrimination but somewhat limited in that they only record callbacks and do not provide further insight as to why. Also, recruiters screened "paper people". This has been criticized but is what recruiters most often do when they initially screen "real" applicants either by means of paper resumes or video resumes (e.g., Hiemstra, Derous, Serlie, \& Born, 2011). Whereas previous studies mainly tested students we investigated real recruiters, thereby enhancing the ecological validity of our study findings. However, because our correspondence audit test did not control for recruiter characteristics, we suggest future research to investigate whether discriminatory effects of ethnic identifiers may depend on real recruiters' characteristics like prejudiced attitudes towards Arabs (Derous et al., 2012) or status legitimating worldviews (O’Brien \& Major, 2005). For instance, in a series of lab studies, Kaiser and Pratt-Hyatt (2009) showed moderating effects of both evaluators' and minority targets' endorsement of status legitimating worldviews on majorities' prejudiced attitudes towards ethnic minorities.

Practical implications. Anonymous resume screening is much debated in Dutch society and findings from practitioners seem inconsistent. Recently, several Dutch cities (like the City of Nijmegen) implemented anonymous resume screening but later abandoned this initiative because of mixed findings (i.e., in terms of number of ethnic minorities that applied and that were hired). Our results seem to suggest that blotting names might be useful in the first stage of the hiring 
procedure. However, it might not be sufficient enough to prevent hiring discrimination because of other, more subtle ethnic identifiers on resumes (like affiliations). Our field study illustrates the complex nature of resume screening and we suggest that both multiple categorization as well as within-categorization processes may explain mixed findings regarding the effectiveness of anonymous resume screening. We therefore recommend recruiters use structured sifting processes, with competency and experience checklists. Competency checklists may allow collecting job relevant information from candidates. This information could be measured quantitatively so that it is possible to rank-order applicants and to track predictions. As such, a standardized approach may be developed for evaluating candidates that eliminates potential subjective biases and inconsistencies. However, since individual differences (like status legitimizing beliefs) may also play a part, screening and training recruiters may be another fruitful intervention. As shown in this study, the adverse impact of resume screening might depend on the level of ethnic identification a resume conveys and recruiters might not be aware of this. Interventions like recruiter training may boost the reliability of resume evaluations (e.g., through frame of reference training).

There are also some practical implications for applicants as well as job seekers' counselors. By investigating applicants' strength of ethnic in-group identification information as revealing from resumes, job seekers' counselors may be able to identify and coach those minorities that may be most "at risk" and particularly vulnerable to hiring discrimination during early recruitment. Theoretically, providing more personalized information should result in less categorization but this effect might highly depend on the type and degree of ethnic identification information that is revealed in resumes. For instance, applicants' affiliation with certain sociocultural groups could harm instead of enhance one's future job chances. In a related vein, 
minorities' phenotypic stereotypicality (the degree an applicant looks like a member of a racial group; Maddox, 2004) could explain differential labor market access of equally qualified but differentially racial-identified minorities. Hence, a within-categorization approach might explain why certain minorities from the same ethnic/racial in-group may experience more actual prejudice than others. This in turn pleads for more tailored and targeted approaches in averting hiring discrimination against minorities with similar ethnic/racial backgrounds but different strengths of ethnic/racial in-group identification.

Conclusion. While practitioners recognize that resume screening results in screening out large numbers of applicants, this stage of the selection process remains under-researched, particularly regarding its adverse impact and issues of discrimination of Arab ethnics. Results of an unobtrusive field experiment suggest that hiring discrimination of ethnic minority applicants depend on the degree of ethnic identification and intersection with sex. Future research may help organizational decision makers to further understand combined effects of applicant, job and rater characteristics on resume screening to limit ethnic discrimination upon organizational entry.

\section{References}

Ashkanasy, N. M., Härtel, C. E. J., \& Daus, C. S. (2002). Diversity and emotion: The new frontiers in organizational behavior research. Journal of Management, 28, 307-338. doi: $10.1177 / 014920630202800304$

Bendick, M., Jr., Jackson, C., Reinoso, V., \& Hodges, L. (1991). Discrimination against Latino job applicants: A controlled experiment. Human Resource Management, 30, 469-484. doi: $10.1002 / \mathrm{hrm} .3930300404$

Bennington, L., \& Wein, R. (2002). Aiding and abetting employer discrimination: The job applicant's role. Employee Responsibilities and Rights Journal, 14, 3-16. doi: 10.1023/A:1015710311395 
Berdahl, J., \& Moore, C. (2006). Workplace harassment: Double jeopardy for minority women. Journal of Applied Psychology, 91, 426-436. doi: 10.1037/0021-9010.91.2.426

Bertrand, M., \& Mullainathan, S. (2004). Are Emily and Greg more employable than Lakisha and Jamal? A field experiment on labor market discrimination. American Economic Review, 94, 991-1013. doi: 10.1257/0002828042002561

Blom, M., Oudhof, J., Bijl, R.V. \& Bakker, B.F.M. (Eds.) (2005). Verdacht van criminaliteit. Allochtonen en autochtonen nader bekeken. [Suspected from criminal facts: A comparsion between ethnic minorities and majorities]. The Hague, the Netherlands: WODC.

Bobko, Ph., \& Roth, Ph. L. (2010). An analysis of two methods for assessing and indexing adverse impact: A disconnect between the academic literature and some practice. In J. L. Outtz (Ed.), Adverse impact: Implications for organizational staffing and high stakes selection (pp. 201-225). New York: Routledge.

Bobko, Ph., Roth Ph. L., \& Buster, M. (2005). Work sample selection tests and expected reduction in adverse impact: A cautionary note. International Journal of Selection and Assessment,13, 1-10. doi: 10.1111/j.0965-075X.2005.00295.x

Brewer, M. B., \& Harasty Feinstein, A. S. (1999). Dual processes in the cognitive representation of persons and social categories. In S. Chaiken, \& Y. Trope (Eds.), Dual process theories in social psychology (pp. 255-270). New York: Guilford Press.

Browne, I., Hewitt, C., Tigges, L., \& Green, G. (2001). Why does job segregation lead to wage inequalilty among African Americans? Person, place, sector, or skills? Social Science Research, 30, 473-495. doi:10.1006/ssre.2001.0708

Browne, I. \& Misra, J. (2003). The intersection of gender and race in the labor market. Annual Review of Sociology, 29, 487-513. doi:10.1146/annurev.soc.29.010202.100016 
Bruning, J. L., Polinko, N. K., Zerbst, J. I., \& Buckingham, J. T. (2000). The effect on expected job success of the connotative meanings of names and nicknames. Journal of Social Psychology, 140, 197-201. doi: 10.1080/00224540009600459

Caglar, A. (2004). Recruitment in the Turkish police. Policing \& Society, 14, 3348-364. doi: $10.1080 / 1043946042000286065$

Carlsson, M., \& Rooth, D. O. (2008). Is it your foreign name or foreign qualifications? An experimental study of ethnic discrimination in hiring. Discussion Paper No. 3810. Bonn: Institute for the Study of Labor (IZA).

Chan, D., \& Schmitt, N. (1997). Video-based versus paper-and-pencil method of assessment in situational judgment tests: Subgroup differences in test performance and face validity perceptions. Journal of Applied Psychology, 82, 143-159. doi: 10.1037/00219010.82 .1 .143

Dean, M. A., Roth, P. L., \& Bobko, Ph. (2008). Ethnic and gender subgroup differences in assessment center ratings: A meta-analysis. Journal of Applied Psychology, 93, 685-691. doi: 10.1037/0021-9010.93.3.685.

De Beijl, R. Z. (2000). Documenting discrimination against migrant workers in the labor market: A comparative study of four European countries. Geneva, Switzerland: International Labor Office.

Derous, E., Nguyen, H. H., \& Ryan, A.M. (2009). Hiring discrimination against Arab minorities: Interactions between prejudice and job characteristics. Human Performance, 22, 1-24. doi: 10.1080/08959280903120261

Derous, E., Ryan, A. M., \& Nguyen, H-H. D. (2012). Multiple categorization in resume screening: Examining effects on hiring discrimination against Arab applicants in field 
and lab settings. Journal of Organizational Behavior. Advance online publication. doi: 10.1002/job.769

Dovidio, J. F., \& Gaertner, S. L. (2000). Aversive racism in selection decisions: 1989 and 1999. Psychological Science, 11, 315-319. doi: 10.1111/1467-9280.00262

Erwin, P. G. (1999). Attractiveness of first names and academic achievement. Journal of Psychology: Interdisciplinary and Applied, 133, 617-620. doi: $10.1080 / 00223989909599767$

Fiske, S. T., Lin, M., \& Neuberg, S. L. (1999). The continuum model, ten years later. In S. Chaiken, \& Y. Trope (Eds.), Dual process theories in social psychology (pp. 231-254). New York: Guilford Press.

Goldman, B. M., Gutek, B. A., Stein, J. H., \& Lewis, K. (2006). Employment discrimination in organizations: Antecedents and consequences. Journal of Management, 32, 786-830. doi: $10.1177 / 0149206306293544$

Ghumman, S. \& Jackson, L. (2010). The downside of religious attire: The Muslim headscarf and expectations of obtaining employment. Journal of Organizational Behavior, 31, 4-23. doi: 10.1002/job.601

Hanges, P. J. \& Feinberg, E. G. (2010). International perspectives on adverse impact: Europe and beyond. In J. L. Outtz (Ed.), Adverse impact: Implications for organizational staffing and high stakes selection (pp. 349-373). New York: Routledge.

Hiemstra, A., Derous, E., Serlie, A., \& Born, M. Ph. (2011, June). Perceptions of video resumes among recruiters and culturally diverse applicants. Paper presented at the EAWOP Small Group Meeting, Athens, Greece.

Higuera, L. (2001). Adverse impact in personnel selection : The legal framework and test bias. 
European Psychologist, 6, 103-111. doi:10.1027//1016-9040.6.2.103.

Horverak, J. G., Bye, H. H., Sandal, G. M., \& Ståle Pallesen, S. (2011). Managers' evaluations of immigrant job applicants: The Influence of acculturation strategy on perceived personprganization fit (P-O Fit) and Hiring Outcome. Journal of Cross-Cultural Psychology. Advance online publication. doi: 10.1177/0022022111430256

Kaas, L. \& Manger, C. (2011). Ethic discrimination in Germany's labor market: A field experiment. German Economic Review. Advance online publication. doi: 10.1111/j.1468-0475.2011.00538.x

Kaiser, C. R., \& Pratt-Hyatt, J. S. (2009). Distributing prejudice unequally: Do Whites direct their prejudice toward strongly identified minorities? Journal of Personality and Social Psychology, 96, 432-445. doi: 10.1037/a0012877

Kulik, C. T., Roberson, L., \& Perry, E. L. (2007). The multiple-category problem: Category activation and inhibition in the hiring process. Academy of Management Review, 32, 529548. Retrieved from http://www.aom.pace.edu/amr/

Levin, S., Sinclair, S., Veniegas, R. C., \& Taylor, P. L. (2002). Perceived discrimination in the context of multiple group memberships. Psychological Science, 13, 557-560. doi: $10.1111 / 1467-9280.00498$

Lonsway, K. A. (2003). Tearing down the wall: Problems with consistency, validity, and adverse impact of physical agility testing in police selection. Police Quarterly, 6, 237-277. doi: $10.1177 / 1098611103254314$.

Maddox, K. B. (2004). Perspectives on racial phenotypicality bias. Personality and Social Psychology Review, 8, 383-401. doi: 10.1207/s15327957pspr0804_4

Moscoso, S. (2000). Selection Interview: A review of validity evidence, aAdverse impact and 
applicant reactions. International Journal of Selection and Assessment, 8, 237-247.

doi: 10.1111/1468-2389.00153.

Nelson, N. L., \& Probst, T. M. (2004). Multiple minority individuals: Multiplying the risk of workplace harassment and discrimination. In J. L. Chin (Ed.), The psychology of prejudice and discrimination: Ethnicity and multiracial identity (pp. 193-217). Westport, CT: Praeger Publishers/Greenwood Publishing Group, Inc.

O’Brien, L. T., \& Major, B. (2005). System-justifying beliefs and psychological well-being: The roles of group status and identity. Personality and Social Psychology Bulletin, 31, 17181729. doi: $10.1177 / 0146167205278261$

OECD (2008). The labor market integration of immigrants and their children in the Netherlands. Paris: Organization for Economic Cooperation and Development.

Ones, D. S., \& Anderson, N. (2002). Gender and ethnic group differences on personality scales in selection: Some British data. Journal of Occupational and Organizational Psychology, 75, 255-276. doi: 10.1348/096317902320369703

Piotrowski, C. \& Armstrong, T. (2006). Current recruitment and selection practices: A national survey of Fortune 1000 firms. North American Journal of Psychology, 8, 489-496.

Pulakos, E. \& Schmitt, N. (1996). An evaluation of two strategies for reducing adverse impact and their effects on criterion related validity. Human Performance, 9, 241-258. doi: 10.1207/s15327043hup0903_4.

Potosky, D., Bobko, P., \& Roth, P. L. (2005). Forming composites of cognitive ability and alternative measures to predict job performance and reduce adverse impact: Corrected estimates and realistic expectations. International Journal of Selection and Assessment, 13, 304-315. doi: 10.1111/j.1468-2389.2005.00327.x. 
Riach, P. A., \& Rich, J. (2002). Field experiments of discrimination in the market place. The Economic Journal, 112, 480-518. doi: 10.1111/1468-0297.00080.

Riordan, C. M., Schaffer, B. S., \& Stewart, M. M. (2005). Relational demography within groups: Through the lens of discrimination. In R. L. Dipboye \& A. Colella (Eds.), Discrimination at work: The psychological and organizational bases (pp. 37-62) (SIOP Organizational Frontiers Series). Mahwah, NJ: Lawrence Erlbaum.

Ryan, A, M., Ployhart, R., \& Friedel, L. (1998). Using personality testing to reduce adverse impact: A cautionary note. Journal of Applied Psychology, 83, 298-307. doi: $10.1037 / 0021-9010.83 .2 .298$

Sidanius, J., \& Pratto, F. (1999). Social dominance: An intergroup theory of social hierarchy and oppression. New York: Cambridge University Press.

Tippins, N. T. (2010). Adverse impact in employee selection procedures from the perspective of an organizational consultant. In J. L. Outtz (Ed.), Adverse impact: Implications for organizational staffing and high stakes selection (pp. 201-225). New York: Routledge.

Zedeck, S. (2010). Adverse impact: History and evolution. In In J. L. Outtz (Ed.), Adverse impact: Implications for organizational staffing and high stakes selection (pp. 3-27). New York: Routledge. 
Table 1

Logistic Regression of Rejection of Resumes on Ethnic Name, Ethnic Affiliation, and Sex

\begin{tabular}{|c|c|c|c|c|c|}
\hline & $B$ & $\mathrm{SE}(B)$ & Wald $^{\mathrm{d}}$ & $\operatorname{Exp}(B)$ & CI $(95 \%)$ \\
\hline Constant & -1.79 & .44 & 16.51 & .17 & -- \\
\hline Name $^{\mathrm{a}}$ & 1.20 & .54 & $4.86^{*}$ & 3.33 & $1.14-9.72$ \\
\hline Affiliation $^{\mathrm{b}}$ & 1.41 & .54 & $6.74^{* *}$ & 4.08 & $1.41-11.79$ \\
\hline $\operatorname{Sex}^{\mathrm{c}}$ & -.92 & .74 & 1.53 & .40 & $.09-1.71$ \\
\hline Name $\mathrm{x}$ Affiliation & 2.90 & 1.19 & $5.90^{* *}$ & 18.09 & $1.75-18.71$ \\
\hline Name $x$ Sex & 2.39 & .87 & $7.58^{* *}$ & 10.93 & $1.99-59.9$ \\
\hline Affiliation $\mathrm{x}$ Sex & 1.47 & .86 & 2.95 & 4.35 & $.81-23.26$ \\
\hline Name $x$ Affiliation $x$ Sex & -3.52 & 1.58 & $4.99^{*}$ & .03 & $.01-.65$ \\
\hline
\end{tabular}


Table 2

Paired-wise Comparison of Rejection Rates of Applicant Profiles

\begin{tabular}{|c|c|c|c|c|c|}
\hline \multicolumn{4}{|c|}{ Applicant profiles (across gender) } & \multirow{2}{*}{$\frac{\chi^{2}(1)}{38.72 * *}$} & \multirow{2}{*}{$\begin{array}{l}p^{c} \\
.00\end{array}$} \\
\hline 1.1 & $\begin{array}{l}\text { Dutch name x Dutch affiliation } \\
\text { (highly Dutch profile) }\end{array}$ & vs. & $\begin{array}{l}\text { Dutch name x Arab affiliation } \\
\text { (mixed Dutch-Arab profile) }\end{array}$ & & \\
\hline 1.2 & $\begin{array}{l}\text { Dutch name x Dutch affiliation } \\
\text { (highly Dutch profile) }\end{array}$ & vs. & $\begin{array}{l}\text { Arab name and Dutch affiliation } \\
\text { (mixed Arab-Dutch profile) }\end{array}$ & $32.82 * *$ & .00 \\
\hline 1.3 & $\begin{array}{l}\text { Dutch name x Dutch affiliation } \\
\text { (highly Dutch profile) }\end{array}$ & vs. & $\begin{array}{l}\text { Arab name and Arab affiliations } \\
\text { (highly Arab profile) }\end{array}$ & $72.43 * *$ & .00 \\
\hline 1.4 & $\begin{array}{l}\text { Dutch name and Arab affiliation } \\
\text { (mixed Dutch-Arab profile) }\end{array}$ & vs. & $\begin{array}{l}\text { Arab name and Dutch affiliation } \\
\text { (mixed Arab-Dutch profile) }\end{array}$ & .41 & .52 \\
\hline 1.5 & $\begin{array}{l}\text { Dutch name and Arab affiliation } \\
\text { (mixed Dutch-Arab profile) }\end{array}$ & vs. & $\begin{array}{l}\text { Arab name and Arab affiliations } \\
\text { (highly Arab profile) }\end{array}$ & $9.03 * *$ & .00 \\
\hline 1.6 & $\begin{array}{l}\text { Arab name and Dutch affiliation } \\
\text { (mixed Arab-Dutch profile) }\end{array}$ & vs. & $\begin{array}{l}\text { Arab name and Arab affiliations } \\
\text { (highly Arab profile) }\end{array}$ & $13.12 * *$ & .00 \\
\hline \multicolumn{2}{|c|}{ Applicant profiles (males vs. females) } & & & $\chi^{2}(1)$ & $p$ \\
\hline 2.1 & Dutch name x Dutch affiliation (males) & vs. & Dutch name x Dutch affiliation (females) & .33 & .56 \\
\hline 2.2 & Dutch name and Arab affiliation (males) & vs. & Dutch name and Arab affiliation (females) & .19 & .66 \\
\hline 2.3 & Arab name and Dutch affiliation (males) & vs. & Arab name and Dutch affiliation (females) & $11.19^{* *}$ & .00 \\
\hline 2.4 & Arab name and Arab affiliations (males) & vs. & Arab name and Arab affiliations (females) & 1.00 & .32 \\
\hline
\end{tabular}


Table 3

Selection Rates (SR) and Adverse Impact-ratios (AI-ratios) according to the Four-Fifth Rule for the Four Applicant Profiles / Resumes

\begin{tabular}{|c|c|c|c|c|c|c|c|c|c|c|c|c|c|c|c|c|}
\hline & & \multicolumn{3}{|c|}{ SRs (\% Accept) } & \multicolumn{12}{|c|}{ AI-ratios ( four-fifth rule) } \\
\hline & & \multirow[t]{2}{*}{ Total } & \multirow[t]{2}{*}{ Female } & \multirow[t]{2}{*}{ Male } & \multicolumn{4}{|c|}{ Total $^{b}$} & \multicolumn{4}{|c|}{ Female $^{c}$} & \multicolumn{4}{|c|}{ Male $^{d}$} \\
\hline \multicolumn{2}{|c|}{ Applicant profile ${ }^{a}$} & & & & 1. & 2. & 3. & 4. & 1. & 2. & 3. & 4. & 1. & 2. & 3. & 4. \\
\hline 1. & $\begin{array}{l}\text { Dutch name x Dutch affiliation } \\
\text { (highly Dutch-identified) }\end{array}$ & $\begin{array}{c}.92 \\
(.74)^{d}\end{array}$ & $\begin{array}{c}.91 \\
(.73)\end{array}$ & $\begin{array}{c}.94 \\
(.75)\end{array}$ & $(.74)^{e}$ & & & & $(.73)$ & & & & $(.75)$ & & & \\
\hline 2. & $\begin{array}{l}\text { Dutch name x Arab affiliation } \\
\text { (mixed Dutch-Arab identified) }\end{array}$ & $\begin{array}{c}.48 \\
(.38)\end{array}$ & $\begin{array}{c}.54 \\
(.43)\end{array}$ & $\begin{array}{c}.40 \\
(.32)\end{array}$ & $.52^{*}$ & $(.38)$ & & & $.59 *$ & $(.43)$ & & & $.43^{*}$ & $(.32)$ & & \\
\hline 3. & $\begin{array}{l}\text { Arab name x Dutch affiliation } \\
\text { (mixed Arab-Dutch identified) }\end{array}$ & $\begin{array}{l}.54 \\
(.43)\end{array}$ & $\begin{array}{l}.72 \\
(.58)\end{array}$ & $\begin{array}{c}.34 \\
(.27)\end{array}$ & $.59^{*}$ & .89 & $(.43)$ & & $.79 *$ & $.75^{*}$ & $(.58)$ & & $.36^{*}$ & .85 & $(.27)$ & \\
\hline 4. & $\begin{array}{l}\text { Arab name x Arab affiliation } \\
\text { (highly Arab-identified) }\end{array}$ & $\begin{array}{l}.14 \\
(.11)\end{array}$ & $\begin{array}{l}.11 \\
(.09)\end{array}$ & $\begin{array}{l}.17 \\
(.14)\end{array}$ & $.15^{*}$ & $.29 *$ & $.26^{*}$ & $(.11)$ & $.12^{*}$ & $.20^{*}$ & $.15^{*}$ & $(.09)$ & $.18^{*}$ & $.43 *$ & $.50 *$ & (.14) \\
\hline
\end{tabular}

Note. ${ }^{a}$ Profile $1=$ the highly Dutch-identified profile with both a Dutch name and affiliation; Profile $2=$ the mixed Dutch-Arab identified profile with a Dutch name and Arab affiliation; Profile $3=$ the mixed Arab-Dutch identified profile with an Arab name and Dutch affiliation; Profile $4=$ the highly Arab-identified profile with both an Arab name and affiliation; ${ }^{b} N$ total resumes $=400(n=100$ resumes per applicant profile $) ;{ }^{c} N$ female resumes $=212(n=53$ resumes per applicant profile); ${ }^{\mathrm{d}} N$ male resumes $=188\left(n=47\right.$ resumes per applicant profile); ${ }^{\mathrm{e}} 80 \%$ of the SRs

(Selection Rates) are presented between brackets. * indicates Adverse Impact (AI) according to the four-fifth rule. 


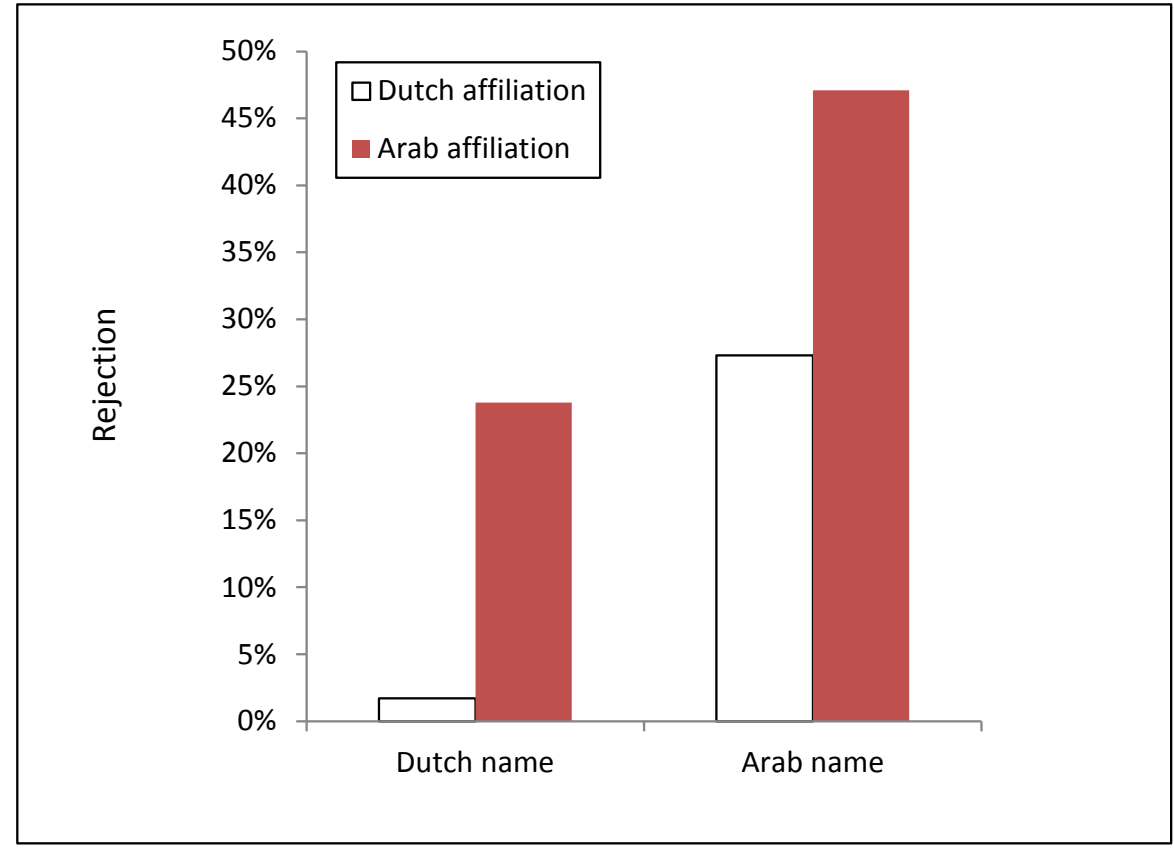

Figure 1. Name by affiliation interaction 


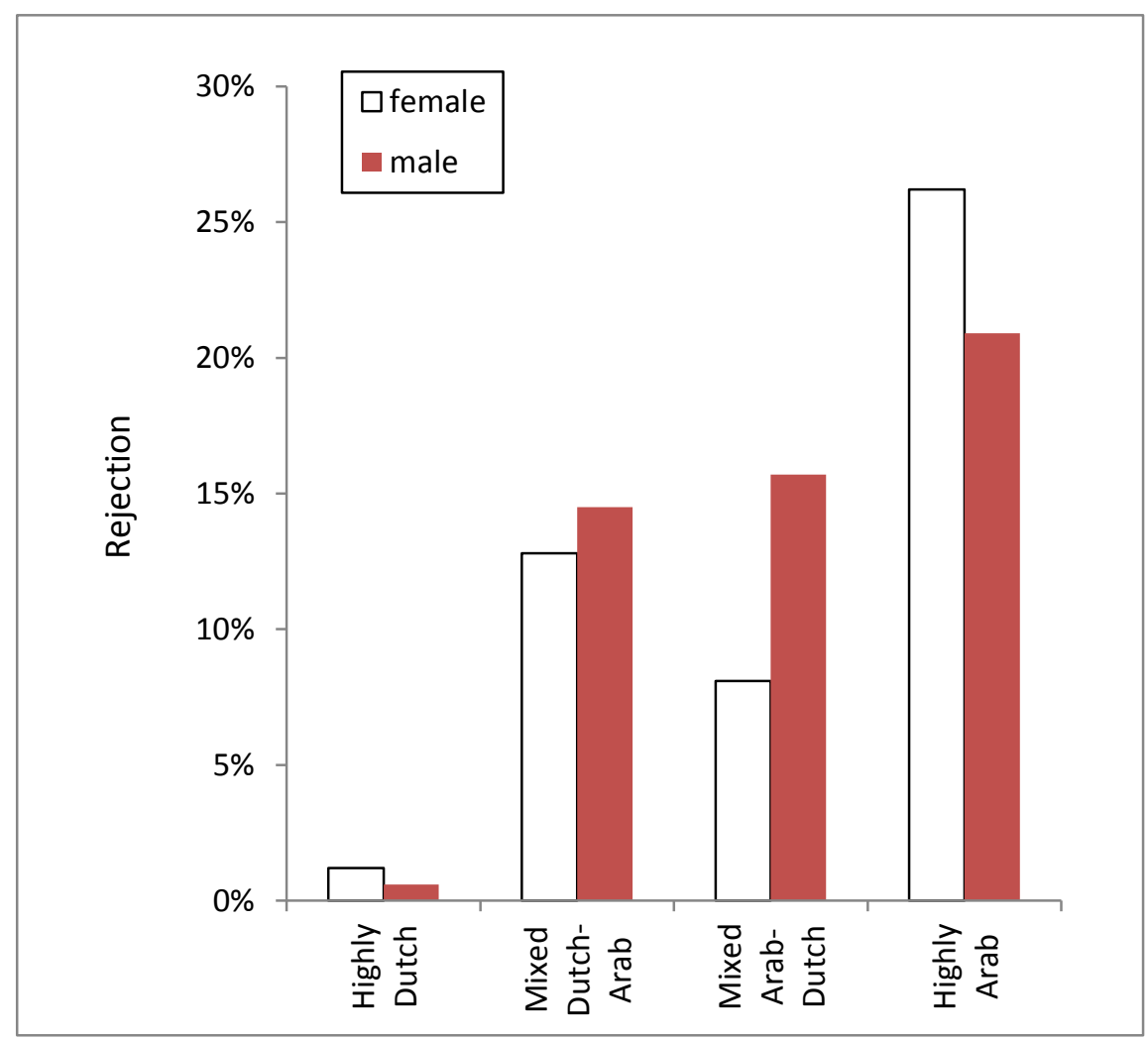

Figure 2. Rejection rates of the four ethnic profiles (Name $\mathrm{x}$ Affiliation) by applicants'sex 